\title{
Trend Analysis on Air Quality and Lung Function - A Case of Consar Stone Quarry Limited, Barekese
}

\author{
Ernest Oti Amankwah ${ }^{1, \dagger, *}$, Godfred Owusu-Boateng ${ }^{2}$, Asare Barima Maxwell ${ }^{3, \dagger, *}$ \\ ${ }^{1}$ Department of Materials Engineering, Kwame Nkrumah University of Science and Technology, Kumasi, Ghana \\ ${ }^{2}$ Department of Fisheries and Watershed Management, Kwame Nkrumah University of Science and Technology, Kumasi, Ghana \\ ${ }^{3}$ Department of Applied Statistics, University for Development Studies, Temale, Ghana
}

\section{Email address:}

otiawere2000@yahoo.com (E. O.Amankwah), abmaxwel19@gmail.com (A. B. Maxwell)

${ }^{*}$ Corresponding author

$\dagger$ Ernest Oti Amankwah and Asare Barima Maxwell are co-first authors.

\section{To cite this article:}

Ernest Oti Amankwah, Godfred Owusu-Boateng, Asare Barima Maxwell. Trend Analysis on Air Quality and Lung Function - A Case of Consar Stone Quarry Limited, Barekese. American Journal of Environmental and Resource Economics. Vol. 4, No. 2, 2019 , pp. $44-53$. doi: $10.11648 /$ j.ajere.20190402.11

Received: March 7, 2019; Accepted: April 28, 2019; Published: May 31, 2019

\begin{abstract}
Air pollution emanating from particulate matter exposure has been identified as a major environmental problem worldwide. The stone quarry industry generates enormous amount of particulate matter into the atmosphere because of activities like blasting, crushing and haulage. The study determined the levels of $\mathrm{PM}_{10}$ and TSP concentrations (using IOM dust samplers) as well as lung function indicators of inhabitants of the Consar Stone Quarry concessional area from November 2015 to March 2016. $\mathrm{PM}_{10}$ concentration exceeded the WHO guideline value $\left(50 \mu \mathrm{gm}^{-3}\right)$ and the permissible EPA-Ghana standard of $70 \mathrm{\mu gm}^{-3}$ except in the month of November and March. The measured TSP concentrations were generally below the EPA Ghana standard of $230 \mathrm{\mu gm}^{-3}$ except for January and December that recorded concentrations above the EPA-Ghana standard probably due to the low relative humidity resulting from scarcity in rainfall and high atmospheric temperature. Measured lung function indicators were significantly higher than the predicted values suggesting adverse effect of the quarry on inhabitants of the concessional area.
\end{abstract}

Keywords: Particulate Matter, Concentration, Concessional Area, Significant, Adverse Effect

\section{Introduction}

Stone has been a resource since ancient times. The Stone Age brought about awareness of the uses of stone and its derivatives. Stone aggregates are used for various purposes that include building, decoration; industrial purposes, lime burning, and production of cement. Stone is however obtained from quarrying, making this activity an important component of man's existence [1]. Vapour, smoke and dust produced during quarry activities are mainly solid materials suspending in the air for a long period. However, particles suspending in the air are capable of travelling to areas very far from point of generation [2]. Particulate matter (PM) has detrimental effects on health when exposed to very low concentrations. $\mathrm{PM}_{10}$ causes diseases such as asthma, cancer of the lung and other cardiovascular diseases [3]. [28] argues that quarry operations result in diverse negative health and environmental effects on nearby communities. Some negative impacts which arise from quarry operations apart from land degradation include creation of swamps, ground water deterioration, biodiversity loss, reduced plant growth, soil erosion, percussions and noise [4]. The impact has the potential to cause lung diseases (which may include silicosis-scarring of the lung tissue and other respiratory diseases like catarrh or common cold, cough, whistling chest), destruction of buildings and water-borne or water related diseases [29]. A very high morbidity is associated with the industry. Quarry activities generate different forms of dusts which are carcinogenic when inhaled. In most African countries of which Ghana is inclusive, pollution exposure emanating from quarry operations is of most environmental importance. It is pathetic that in view of the effect, studies are often carried out only on those employed 
within these quarry companies. Occupationally, those who live within the catchment areas are mostly overlooked. Hence, the study examined the air quality and the lung function of communities within the concessional area of the Consar Stone Quarry Limited with special emphasis on both employees and ordinary inhabitants. The stone aggregates are used in the construction of buildings, roads, bridges and other structures. This has led to the provision of jobs for many people. In totality, the industry has remarkably contributed to the socioeconomic development of Ghana. However, it has many adverse impacts on the environment which include healthrelated issues to humans, generation of large volumes of dust, cracks in buildings, loss in biodiversity among others. Several communities inhabit the concessional area of Consar Stone Quarry Limited at Barekese. The likelihood that the quarry exerts adverse effect on the health of both humans and the environment cannot be ruled out. The size of dust particles determines the health effects it poses. Dust pollution has been a contributory factor to many recorded cases of respiratory diseases. There has been a serious concern raised by people in the study area on the impacts of dust run-offs and vibrations emanating from the quarry site on the health of the surrounding communities. The concerns of the people are valid because Environmental Protection Agency (EPA) guidelines requires that quarrying activities should not cause annoyance around residence, educational centers like schools, or hospitals. The communities have complained severally about the quarry operations due to the effects of deposited dust particles especially the contrast in colour when they settle, on surfaces such as edges of windows, louver blades and other window surfaces, cars, doors and tables. Therefore, assessment of the air quality $\left(\mathrm{PM}_{10}\right.$ and $\left.\mathrm{TSP}\right)$ and health risk would help authorities of the quarry to take the necessary measures to curb any human and environmental hazards associated with such situations. Knowledge generated from such assessment would help law enforcement agencies in limiting the menace. The following question motivated the research: What is the level of Particulate Matter below 10 microns (PM 10 ) and Total Suspended Particles (TSP) in the ambient air of the study area?, What is the health risk affecting the inhabitants and the measures available to arrest the situation at Barekese and its environs?

The study is to identify the air quality and lung function of communities found within the catchment area of the Consar Stone Quarry Limited. The notable effect on the people living in this area is adequately monitored by measuring the level of $\mathrm{PM}_{10}$ and TSP of the surrounding air. Particulate matter (PM) refers to suspended particles (solid and liquid mixture) in the air. Emission of particulate matter into the air is mostly from anthropogenic and natural sources while TSP refers to Total Suspended Particles (TSP).

\section{Methods and Materials}

\subsection{Study Area}

The study areas that include the Consar Stone Quarry site,
Barekese Zongo and Poho are located in the Atwima Nwabiagya District in the Ashanti Region of Ghana.

According to the Ghana's 2010 population and housing census (PHC), the district covers an estimated land area of $294.84 \mathrm{~km}^{2}$ and has 126 settlements. The district has a population of 149,025 . Of this, 71948 are males and 77,077 are females. Majority (68.5\%) of the indigenes in the district are rural settlers. Atwima Nwabiagya District is located within the wet semi-equatorial zone. Throughout the year, the rainfall range is between $1700 \mathrm{~mm}$ and $1850 \mathrm{~mm}$. annually, the rainfall distribution pattern is not even. The pattern and density of the rainfall is unpredictable and poses substantial risk to rain-fed agriculture. The district has a fairly uniform temperature range of $27^{\circ} \mathrm{C}-31^{\circ} \mathrm{C}$ and a humidity range of $87 \%-91 \%$ [5]. The abundance of granite rocks in Barekese is responsible for a number of quarry companies in the area. In addition, the readiness of market within the Kumasi city because of rapid urban expansion account for the high demand of quarry products for various construction works. Mostly, the vegetation type is semi-deciduous. The district can boast of various types of rocks that include phyllites, gneiss, greywaches and granite among others. Some of these rocks are of substantial economic importance since they bear precious minerals like gold. Good clay deposits can also be found which are used for brick and ceramic making. Granite deposits in Barekese and Tabere and Ntensere provide dimension stone for the road and building construction. Consar Stone Quarry is located at Barekese about $25 \mathrm{~km}$ away from the Kumasi city. The study areas made of the mine site and two communities located in the concessional area of the quarry. The site is embedded with a lot of granite rocks. The quarry has a large quarry phase, and two crushing points. The study areas include Barekese Zongo and Poho communities. These two selected communities have an estimated total population of 3,730 and are located within the concessional area of the stone quarry.

\subsection{Method of Sampling}

A multi- stage clustering technique was utilized to select the study participants since the study is a quantitative social survey. It was appropriate to use cluster sampling technique because it tends to presume that, the elements in the cluster were just heterogeneous as the total population [6]. Selfstructured research instrument was used to collect data that has been inferentially and statistically analyzed to determine the lung function and respiratory health of the study participants.

In all ninety-five (95) study participants were recruited. Thirty-three (33) participants were workers of the quarry and thirty-one (31) participants each from Barekese Zongo and Poho communities. This sample size is a true representation of about $10 \%$ of the total population of 938 [6]. Particularly, multi-stage clustering sample technique was used to select the representative group of people between the ages of 18 to 55 and who have resided in the area for at least 5 years. This is because lung function has been reported to decrease with increasing age $[7,8]$. 


\subsection{Data Collection}

Data collection for the study involved administration of questionnaire, dust level measurements $\left(\mathrm{PM}_{10}\right.$ and TSP) and testing of lung function of the study participants. The questionnaire crafted for this study was titled "respiratory health questionnaire" Dust monitoring took place at the quarry site (crushing area and the blasting area) and the communities within the catchment area of the quarry (Barekese Zongo and Poho) from November to March. It catered for both the wet and dry seasons. Lung function testing and administering of questionnaires were done in April 2016. At each point of monitoring the dust exposure, there were two Institute of Occupational Medicine (IOM) samplers to measure $\mathrm{PM}_{10}$ and TSP. The monthly monitoring lasted for two days. Usually, the first day was used to monitor particulate levels at the quarry site and the second day was used to monitor particulate levels at the communities. The study participants were administered with the questionnaires and they were given one week period to finish responding. The lung function tests were performed on the study participants simultaneously with anthropometric measurements (age, weight and height).

\subsection{Instrumentation}

The instruments that were used for data collection included: Questionnaire, Vitalograph and Institute of Occupational Medicine (IOM) Samplers (224-52MTXK)

\subsection{Questionnaire}

Quantitative cross-sectional data was collected by the use of self-structured administered questionnaires with standardized closed-ended and sequenced items. In the process of gathering of data, questionnaires administered were of uniformity and standardization. The sociodemographic characteristics of respondents were set and operationalized on nominal level. There was a pilot testing of the questionnaires in order to identify inherent ambiguity in the research instrument. Questionnaire for the pilot study were administered to 15 people by the researcher to confirm that the items to be tested were not ambiguous to understand and as such, the research instruments piloted can be evaluated as effective, easy and proficiently crafted. The questionnaire was administered in both English and Asante Twi depending on the literacy and understanding of the items by the respondents. The questionnaire was administered to the 95 respondents to ascertain their socio-demographic characteristics, medical history, physical activity levels, and household characteristics.

\subsection{Lung Function Test}

A lung function test was conducted among the study participants. The vitalograph was used for the measuring of the lung function of participants. The expiratory parameters measured include Forced Vital Capacity (FVC), Forced Expiratory Flow (FEV $25-75)$, Peak Expiratory Flow (PEF),
Forced Expiratory Volume (FEV1\%), and Forced Expiratory Volume in one second (FEV1).

The ambient room temperature at which the spirometry was conducted was between the temperatures of $23^{\circ} \mathrm{C}$ and $34^{\circ} \mathrm{C}$. Anthropometric details (age, height and sex) of study participants were entered into the vitalograph before the spirometry measurement process began.

The study participants were allowed to relax while a demonstration was made as to how the whole measurement process will be done. Some of the participants were made to rehearse to check accuracy and precision of work but no reading was recorded. Participants were made to put on a nose clip to avoid air from coming out their nose. The participants were then made to undertake the test when it was certified that everything was in order, a correct work can be done. For accuracy, and precision, a number of tests were carried on an individual at least twice to obtain the correct test.

\subsection{Ambient Air Quality}

$\mathrm{PM}_{10}$ and TSP were measured within the study areas (crushing and blasting sites of the stone quarry, Barekese Zongo and Poho communities) using Institute of Occupational Medicine (IOM) sampler (Model: 224-52 MTXK). The samplers are serialized 07518041, 07518042, 07518043, and 07518044. Also, each IOM sampler had its own calibrated flow rate. The filter holder assembly of the sampler was configured purposely to measure $\mathrm{PM}_{10}$ and TSP.

IOM Sampler sampling dust at a location at the Consar Stone Quarry site. The samples were analyzed using the formula below:

$$
\mathrm{PM}_{10} / \mathrm{TSP}\left(\mu g m^{-3}\right)=\frac{w_{2}-w_{1}}{F r \times T}
$$

Where: TSP - Total Suspended Particles

PM10 -Particulate Matter below 10 microns

$w_{1}$-Weight of filter paper before sampling

$w_{2}$ - Weight of filter paper after sampling

$\mathrm{Fr}-$ Flow rate

$\mathrm{T}-$ Sampling period

\section{Results and Discussions}

\subsection{Demographic Characteristics of Study Participants}

As indicated on Table 1 below, the highest participants of 33 (34.8\%) were recruited from the Consar Stone Quarry Limited while 31 (32.6\%) participants were recruited each from Barekese Zongo and Poho Communities. However, males dominate the age category with 59 (62.1\%) whereas females recorded $36(37.9 \%)$.

Approximately, $32(33.6 \%)$ of the participants had their ages ranging from 28 to 37 years followed by those with the ages above 47 years recorded $26(27.4 \%), 18$ to 27 year group recorded $20(21.1 \%)$ while the least record, 17 (17.9\%) for 38 to 47 years. Conversely, participants whose ages were more than 55 years were not included. This is because lung 
function decreases with increasing age as studied by [27] who found a rise in pulmonary function in adolescent boys and peak at age 18 and then fall with rise in age. [9] also, identified in their study a positive relationship when some variables were compared with age.

Table 1. Breakdown of Social Demographic Characteristics.

\begin{tabular}{lll}
\hline Variable & Characteristics & Number of Participants (\%) \\
\hline Study Area & Barekese Zongo & $31(32.6 \%)$ \\
& Consar Stone Quarry Site & $33(34.8 \%)$ \\
& Poho Community & $31(32.6 \%)$ \\
Sex & Female & $36(37.9 \%)$ \\
& Male & $59(62.1 \%)$ \\
Age (years) & $18-27$ & $20(21.1 \%)$ \\
& $28-37$ & $32(33.6 \%)$ \\
& $38-47$ & $17(17.9 \%)$ \\
& $>47$ & $26(27.4 \%)$ \\
\hline
\end{tabular}

\subsection{Ambient Air Quality}

\subsubsection{Trend of PM10 Concentrations at the Sampling Location}

The dynamics of $\mathrm{PM}_{10}$ concentrations showed similar trend for all the sampling locations namely Consar Blasting site, Consar Crushing site, Barekese Zongo and Poho Community. Thus, the $\mathrm{PM}_{10}$ concentration increases from
November to January (where the peaks occurred) and declined to March where the lowest concentrations were recorded for all the locations.

In November, the $\mathrm{PM}_{10}$ concentrations were below the EPA Ghana standard level of $70 \mu \mathrm{gm}^{-3}$ in all the locations except the Consar Blasting Site where $70.88 \mu \mathrm{gm}^{-3}$ was recorded probably because it is a point of generation of dust. In the months of December, January and February concentrations above the EPA Ghana standard were recorded. This may be due to dryness of the air that might have facilitated dispersal of the dust. The weather conditions in December, January and February were relative to those in November and March. This may account for higher $\mathrm{PM}_{10}$ concentrations for the three locations.

An uneven trend of $\mathrm{PM}_{10}$ concentration was recorded at all the sampling locations Figure 1. The lowest concentration of $52.6 \mu \mathrm{gm}^{-3}$ was recorded in the month of November for the Consar Crushing site at temperatures and relative humidity of $23-31^{\circ} \mathrm{C}$ and $78 \%$ respectively. The low concentration recorded may be due to high relative humidity resulting from relatively high rainfall recorded in November. This might have suppressed the dust particles or caused them to settle and therefore are unavailable for capture by the IOM Sampler.

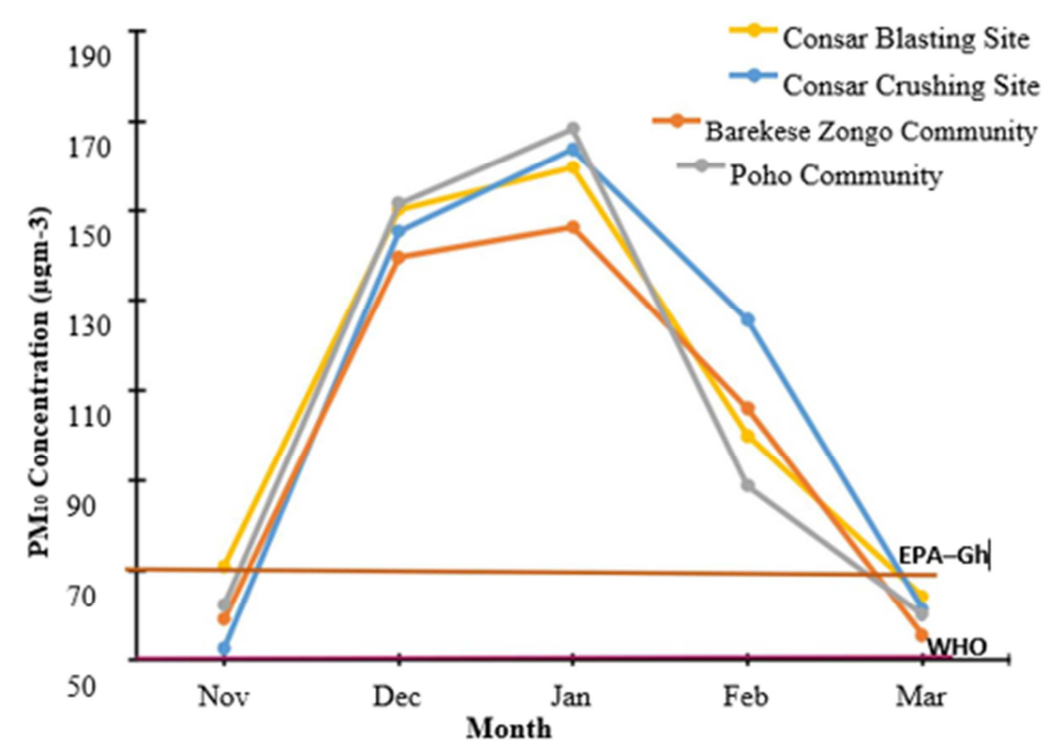

Figure 1. The trend of the dynamics of PM10 concentrations at the sampling locations.

The highest concentration of $168.4 \mu \mathrm{gm}^{-3}$ was recorded in January for the Poho Community at temperatures and relative humidity of $25-39^{\circ} \mathrm{C}$ and $12 \%$ respectively. The highest concentrations of PM10 were recorded in the month of January. This may be attributed to the dryness of the air, which was at its peak in January and thus facilitating dispersal of the dust. This is consistent with studies by [10] and [11] who indicated that particulate matter concentrations increase with increase in temperature as a result of low relative humidity.

The study revealed that the Poho Community recorded the highest $\mathrm{PM}_{10}$ concentration in December and January although it may be expected that the point of generation of the dust (Consar crushing and blasting sites) should record the highest concentrations as in November, February and March. The closeness of the Poho Community (about 10 meters), to the Consar Quarry Site and change in wind direction (North-West to South-East) during the sampling period could account for this observation. This agrees with a study by [2] that particulate matter is able to travel far from the generation source.

Realistically the WHO guideline of $50 \mu \mathrm{gm}^{-3}$, which is stricter than the EPA-Ghana standard of $70 \mu^{-3}{ }^{-3}$, might not be of economic benefit to quarrying in Ghana. However, 
EPA-Ghana setting an allowable threshold up to $70 \mu \mathrm{gm}^{-3}$ considers that this is realistic in terms of economic benefits to quarrying in Ghana therefore arrived at this regulatory standard to check air pollution. The results were compared to EPA-Ghana standard on acceptable $\mathrm{PM}_{10}$ concentrations. The concentrations of $\mathrm{PM}_{10}$ measured in all the sampling locations from December to February exceeded the EPA acceptable limit of $70 \mu \mathrm{gm}^{-3}$. This gives an indication of air pollution within the three months may be attributed to the dry season, which resulted in low relative humidity. In Ghana, the dry season peaks during the months of December, January and February accounting for fast movement and suspension of particulate matter in the air for longer time thereby making particulates easily detected by the IOM samplers for measurement.

[11] citing [12] in his study demonstrated a significant relationship between average $\mathrm{PM}_{10}$ emission levels and mortality at concentrations lower than the existing United States standard of $150 \mu \mathrm{gm}^{-3}$ for short-range of $\mathrm{PM}_{10}$ levels. This study implies that even though industries may be polluting below the WHO and EPA-Ghana standards there might still be some health dangers. [13], conducted a study on over five hundred thousand people in 151 metropolitan areas in the United States and identified that areas mostly polluted with $\mathrm{PM}_{10}$ experience higher death rate about $17 \%$ more than less polluted areas. A research by [14] suggest that any $10 \mu \mathrm{gm}^{-3}$ increase in concentration of annual average PM10 causes a rise in death rate ranging from $0.3 \%-1.6 \%$. This advances the argument that although $\mathrm{PM}_{10}$ concentrations recorded for November $\left(52.55 \mu \mathrm{gm}^{-3}\right.$,
$59.11 \mu \mathrm{gm}^{-3}$ and $\left.62.26 \mu \mathrm{gm}^{-3}\right)$ and March $\left(61.4 \mu \mathrm{gm}^{-3}, 64.1\right.$ $\mu \mathrm{gm}^{-3}, 55.5 \mu \mathrm{gm}^{-3}$ and $60.1 \mu \mathrm{gm}^{-3}$ ) generally, were below the EPA-Ghana standard, the health effect on the people should still be considered as important.

The $\mathrm{PM}_{10}$ concentrations recorded in the months of December, January and February were above the EPA-Ghana standard. These were periods where the atmospheric temperature was relatively high (up to $39^{\circ} \mathrm{C}$ ) and the relative humidity was very low $(12 \%)$ leading to no or little moisture to promote the precipitation of liberate particulates.

This supports the findings by [12] who reported a significant increase in hospital admissions in areas where the $\mathrm{PM}_{10}$ threshold exceeded the United States standard. [15], carried out a study in the United States and identified an association between respiratory symptoms and long term exposure to $\mathrm{PM}_{10}$ concentrations between $30-35 \mu \mathrm{gm}^{-3}$ with no proof of threshold point below which there exist no health implications.

\subsubsection{Trend of TSP Concentrations at Various Sampling Locations}

The trends of measured TSP concentrations were also uneven throughout the sampling period. Generally, the lowest TSP concentrations for all the sampling locations were observed in March where the relative humidity was high and the atmospheric temperature readings were generally low. The highest concentrations for all sampling locations were also recorded in the month of January following a trend similar to that of concentration of $\mathrm{PM}_{10}$ recorded Figure 2.

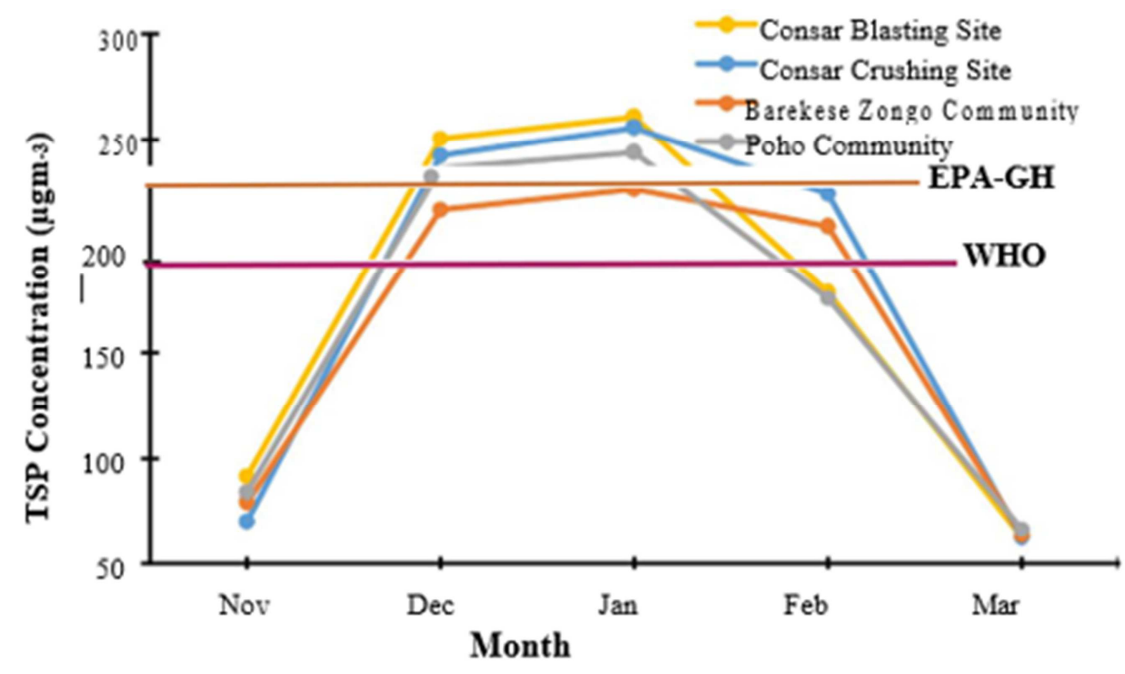

Figure 2. Trend of TSP concentrations at the sampling locations.

The crushing site recorded the lowest TSP concentration of $62.4 \mu \mathrm{gm}^{-3}$ at a temperature and relative humidity of $21-32^{\circ} \mathrm{C}$ and $91 \%$ respectively. The low concentration may be due to high relative humidity restricting particulate matter precipitation and movement. This may cause easy settlement of particulate matter thereby escaping detection by the IOM samplers.

The highest TSP concentration was recorded in the month of January for all sampling locations where the relative humidity was low due to the severe nature of the harmattan. The Consar blasting site recorded the highest TSP

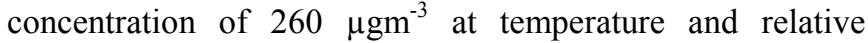
humidity of $24-37^{\circ} \mathrm{C}$ and $14 \%$. The trend of TSP concentration over the period of dust sampling was not constant Figure 2. [11] reiterated that the concentration of particulate matter is uneven over a period of time due to 
change in meteological conditions.

Realistically, economic benefits in Ghana allow quarry operations to be conducted at concentrations not exceeding the EPA-Ghana standard of $230 \mu \mathrm{gm}^{-3}$ for total suspended particles. There was pollution during the months of December and January when concentrations were compared to EPA-Ghana standard for all the sampling locations except Barekese Zongo that recorded concentrations of $217.2 \mu \mathrm{gm}^{-3}$ for and $226.7 \mu \mathrm{gm}^{-3}$ which were below the permissible EPA-Ghana standard of $230 \mu \mathrm{gm}^{-3}$. This may be attributed to the fact that the crushing site and the blasting site are the point of generation of dust and during December and January relative humidity was low (about 17\%). The dry season was severe and atmospheric temperature was high (up to $40^{\circ} \mathrm{C}$ ). Although relatively, the area recorded TSP concentrations below the acceptable EPAGhana standard of $230 \mu \mathrm{gm}^{-3}$ the situation does not necessarily indicate that the area is of safe health. This is because studies conducted in some developed countries which in those by [16] found an association between long-term exposure to particulate matter and respiratory symptoms even within the concentration range of $30-35 \mu \mathrm{gm}^{-3}$.

The TSP concentrations measured compared to WHO guideline of $200 \mu \mathrm{gm}^{-3}$ shows that the study area was polluted in the months of December, January and February. The concentrations exceeded the permissible WHO standard except in the month of February where the crushing site and
Poho community respectively recorded concentrations of $178.5 \mu \mathrm{gm}^{-3}$ and $175.4 \mu \mathrm{gm}^{-3}$ below the of WHO standard of $200 \mu \mathrm{gm}^{-3}$. Realistically, economic benefits in Ghana allow quarry operations to be conducted at concentrations not exceeding the EPA-Ghana standard of $230 \mu \mathrm{gm}^{-3}$.

Generally, the study area is not polluted when compared to EPA-Ghana standard except in the months of December and January Figure 2 where the crushing site, blasting site and the Poho community recorded concentrations above the permissible EPA-Ghana standard of $230 \mathrm{gm}^{-3}$. This may be attributed to the fact that the crushing site and the blasting site are the point of generation of dust and during December and January, the relative humidity was low (about 17\%). The dry season was severe and atmospheric temperature was high (up to $40^{\circ} \mathrm{C}$ ).

\subsubsection{Relationship Between TSP and PM10 Trend}

Concentrations of $\mathrm{PM}_{10}$ and TSP measured at the various sampling locations from November to March shows a direct relationship between TSP and $\mathrm{PM}_{10}$ trends. Averagely, the crushing site and the blasting site recorded the highest concentrations of $109 \mu \mathrm{gm}^{-3}$ and $170.8 \mu \mathrm{gm}^{-3}$ for $\mathrm{PM}_{10}$ and TSP respectively. This may be attributed to the fact that the crushing and blasting sites of the quarry are the point of generation of Particulate matter Figure 3.

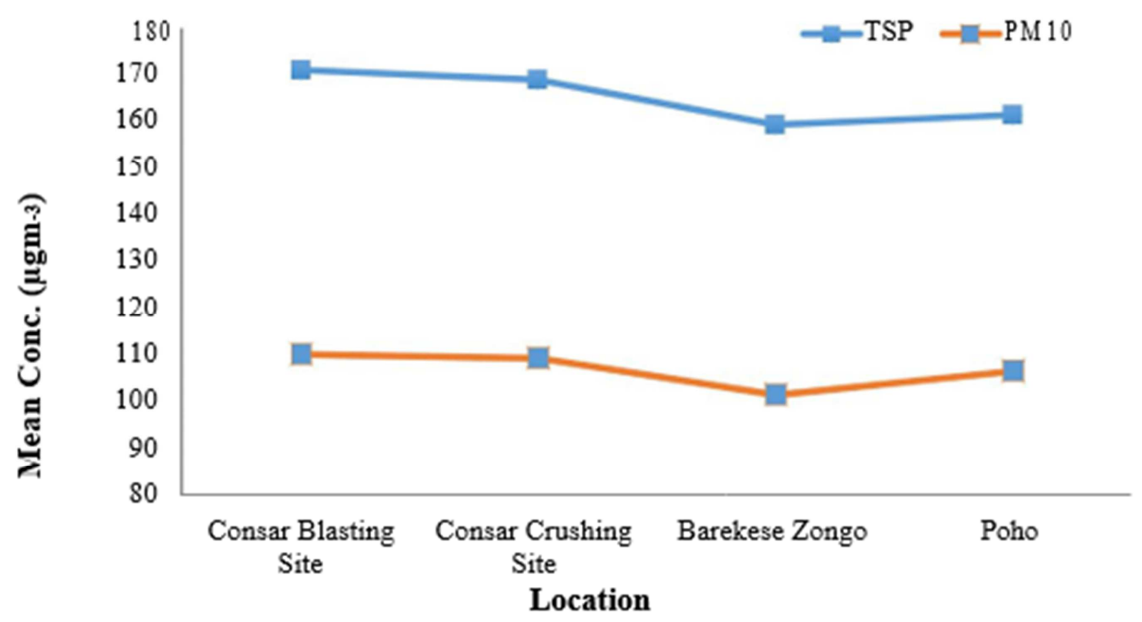

Figure 3. PM10 and TSP concentration distribution at the sampling locations.

The Poho community followed with concentrations of $106 \mu \mathrm{gm}^{-3}$ and $161.4 \mu \mathrm{gm}^{-3}$ for $\mathrm{PM}_{10}$ and TSP respectively. Barekese Zongo recorded the least average concentrations of $102 \mu \mathrm{gm}^{-3}$ and $159.2 \mu \mathrm{gm}^{-3}$ for $\mathrm{PM}_{10}$ and TSP respectively. The Poho Community recorded higher concentrations of $\mathrm{PM}_{10}$ and TSP than Barekese Zongo suggesting the closeness of the Poho community to the quarry site than Barekese Zongo. This was in conformity with [17] who revealed that there exists a direct relationship between measured $\mathrm{PM}_{10}$ and TSP as far as they are generated from the same source and been driven by similar factor like precipitation.

The similarity in trend in $\mathrm{PM}_{10}$ and TSP is therefore not surprising. However, during the rainy seasons, the $\mathrm{PM}_{10}$ is suspended leaving the heavier particulates to settle. This may cause respiratory problems in humans and reduction in photosynthesis in plants when they are deposited on plant leaves.

\subsection{Respiratory Symptoms and Lung Function}

\subsubsection{Comparing Measured and Predicted Lung Function Test}

The lung function parameters measured include Vital Capacity (VC), Forced Vital Capacity (FVC), Forced Expiratory Volume 1 (FEV1), Peak Expiratory Flow (PEF), and Forced Expiratory Flow 25\%-75\% (FEV25\%-75\%). The study revealed a significant difference in the measured and predicted parameters of lung function with $p$-values of 
$<0.000$ Table 2 .

Table 2. Comparison of measured and predicted lung function tests results.

\begin{tabular}{llllllll}
\hline \multirow{2}{*}{ Lung Function } & Measured & \multicolumn{5}{c}{ Predicted } & \multirow{2}{*}{ P-values } \\
\cline { 2 - 8 } & Mean & SD & 95\% CL & Mean & SD & 95\% CL & $<0.00$ \\
VC & 3.28 & 0.79 & $3.12-3.44$ & 3.78 & 0.72 & $3.63-3.93$ & $<.53-3.79$ \\
FVC & 3.31 & 0.79 & $3.15-3.48$ & 3.66 & 0.64 & $<0.00$ \\
FEVI & 2.77 & 0.70 & $2.63-2.92$ & 3.09 & 0.52 & $2.98-3.20$ & $<0.00$ \\
PEF & 6.19 & 1.81 & $5.81-6.56$ & 8.38 & 1.23 & $8.13-8.64$ & $<0.00$ \\
FEF $_{25-75}$ & 3.07 & 1.15 & $2.84-3.31$ & 4.26 & 0.52 & $4.15-4.36$ & $<0.00$ \\
\hline
\end{tabular}

Individuals exposed to particles having aerodynamic diameter lesser than or equal to the nominal ten microns may experience health problems. Some of these particles are capable of penetrating and being retained deep in the lungs. Obstruction in the airways was considered in the results of the measured lung function. Reduced lung function tests show an obstruction in the airways. This culminate in many health problems such as wheezing, coughing, and chest pains which is consistent with a study by [18] who posited that toxicological and epidemiological studies showed a relation between air pollution and adverse health effects.

A level of significance of $5 \%$ was observed to be the difference between measured and predicted lung function tests. The difference in significance level may be due to the ability of particulates to penetrate deep down the respiratory system. On the contrary, defensive mechanisms by the respiratory system are able to remove $99 \%$ of particulate matter bigger than 10 microns inhaled air [19]

\subsubsection{Compared VC, FVC, FEV1, PEF and FEF $25 \%-75 \%$ by Location}

Results indicate significant difference between the measured lung function parameters (VC, FVC, FEV1, PEF and $\mathrm{FEF}_{25 \%-75 \%}$ ) of the study participants in the various locations (Consar quarry site, Barekese Zongo and Poho). Pvalues for the measured lung function were less than the 0.05 significance level as indicated in Table 3 beneath.

Table 3. Lung function compared between Consar quarry site, Barekese Zongo and Poho.

\begin{tabular}{|c|c|c|c|c|}
\hline Lung Function & Location & Mean & SD & P-values \\
\hline \multirow{3}{*}{$\mathrm{VC}$} & Consar quarry site & 3.05 & 0.91 & 0.000 \\
\hline & Barekese Zongo & 3.40 & 0.54 & 0.000 \\
\hline & Poho & 3.40 & 0.54 & 0.000 \\
\hline \multirow{3}{*}{ FVC } & Barekese Zongo & 3.45 & 0.82 & 0.000 \\
\hline & Poho & 3.37 & 0.93 & 0.000 \\
\hline & Consar quarry site & 3.12 & 0.90 & 0.001 \\
\hline \multirow{2}{*}{ FEVI } & Consar quarry site & 2.66 & 0.79 & 0.000 \\
\hline & Poho & 2.76 & 0.68 & 0.003 \\
\hline \multirow{3}{*}{ PEF } & Consar quarry site & 5.75 & 2.03 & 0.000 \\
\hline & Barekese Zongo & 6.49 & 1.77 & 0.000 \\
\hline & Poho & 6.32 & 0.48 & 0.000 \\
\hline \multirow{3}{*}{$\mathrm{FEF}_{25 \%-75 \%}$} & Consar quarry site & 3.05 & 1.13 & 0.004 \\
\hline & Barekese Zongo & 3.29 & 1.10 & 0.001 \\
\hline & Poho & 2.82 & 0.75 & 0.000 \\
\hline
\end{tabular}

This is consistent with a study conducted by [11] at Chirano Gold Mines who found significant difference among two communities where lung function tests were conducted. This may be due to particulate matter concentration being uneven at the various sampling locations at a particular time of measurement.

\subsubsection{Effects of Body Mass Index (BMI) and Age on VC, FVC, FEV1, PEF and FEF $25 \%-75 \%$}

It could be emphasized on Table 4, Body Mass Index (BMI) and age effect on measured lung function parameters (VC, FVC, FEV1, PEF, and $\mathrm{FEF}_{25 \%-75 \%}$ ) showed no significant difference. This may be due to the recorded P-values for BMI and age being greater than the 0.05 level of significance.

Table 4. BMI and Age effect on measured Lung Function.

\begin{tabular}{llllll}
\hline P-value & & & & \\
\hline & VC & FVC & FEVI & PEF & FEF $_{25 \%-75 \%}$ \\
\hline BMI & 0.89 & 0.54 & 0.63 & 0.59 & 0.74 \\
Age & 0.46 & 0.29 & 0.43 & 0.64 & 0.54 \\
\hline
\end{tabular}

This study is therefore inconsistent with findings by [20] who found a progressive rise in Peak Expiratory Flow Rate (PEFR) and arm span per rise in age in children. They witnessed an increase in the PEFR values with increase in age and arm span. In addition, [21] found a positive correlation among lung function variables with height and age among 
some welders and controls. This is therefore contrary to this study which found otherwise. The research is also inconsistent with studies by [22] who reiterated that significant difference is seen when age is compared with lung function variables.

\subsubsection{Some Respiratory Health Symptoms Occurrences in the Study Area}

The study revealed $36.26 \%, 28.26 \%, 39.13 \%, 43.48 \%$ and $8.70 \%$ participants responding "Yes" for shortness of breath, coughing, wheezing, chest pain and medicinal use respectively. Lung function test in addition to symptoms identification is very important when diagnosing for respiratory diseases. Particulates are capable of retarding carbon dioxide and oxygen exchange in the lungs that cause shortness in breath. The lung has to strain itself to compensate for oxygen during this situation. Smaller number of respondents gave negative responses to the respiratory occurrence symptoms as revealed in Table 5 below.

Table 5. Respiratory Symptoms Occurrences of Inhabitants in the Study Area.

\begin{tabular}{lllll}
\hline \multirow{2}{*}{ Respiratory symptom } & Frequency & & \multicolumn{2}{l}{ Percentage (\%) } \\
\cline { 2 - 5 } & Yes & No & Yes & \\
\hline Shortness of breathe & 26 & 69 & 36.26 & \\
Coughing & 26 & 69 & 28.26 \\
Wheezing & 36 & 59 & 39.13 & 71.74 \\
Chest pain & 40 & 55 & 43.48 & 60.87 \\
Medicinal use & 8 & 87 & 5.70 & 91.30 \\
\hline
\end{tabular}

The responses from the study participants do not correlate with the lung function test conducted in the Consar stone quarry site, Barekese Zongo and Poho. [26] in their study on chronic bronchitis prevalence found a prevalence between of $3 \%$ and $17 \%$ in developed countries and $13 \%$ and $27 \%$ in developing countries. Nevertheless, currently there is no credible data on chronic bronchitis prevalence and breathlessness in Ghana. It can be inferred from the results Table 6 that the response from the study participants does not suggest much respiratory or breathing problem on the inhabitants. This is at variance with a study by [16] who found an association between particulate matter exposure and respiratory symptoms but supports [11] who found no significant correlation between long term exposure to particulate matter and symptoms of respiration.

\subsubsection{Effects of Smoking and Vigorous Activities on Lung Function}

The results obtained from Table 6 shows that there exist no significant relation of respondents smoking history and activities (vigorous) on measured VC, FVC, FEV1, PEF and $\mathrm{FEF}_{25 \%-75 \%}$

Table 6. Effect of smoking and vigorous activities on lung function.

\begin{tabular}{|c|c|c|c|c|c|}
\hline \multirow{2}{*}{ Variable } & \multicolumn{5}{|c|}{ P-value } \\
\hline & $\mathrm{VC}$ & FVC & FEVI & PEF & FEF $_{25 \%-75 \%}$ \\
\hline Ever smoked & 0.15 & 0.43 & 0.56 & 0.11 & 0.33 \\
\hline Currently smoking & 0.14 & 0.24 & 0.33 & 0.43 & 0.21 \\
\hline Vigorous activity & 0.32 & 0.36 & 0.12 & 0.53 & 0.54 \\
\hline
\end{tabular}

Smoking status of study participants had no significant difference on the measured lung function parameters, VC, FVC, FEV1, PEF and $\mathrm{FEF}_{25 \%-75 \%}$ since p-values recorded were greater than 0.05 significant level. The study is at variance with a study conducted by [23] in the U.S who found an adverse effect on the pulmonary function growth of cigarette smokers. [23] made a proof that, smoking of cigarette is associated with mild obstruction of the airways and lung function limitations. Investigation of the effect of smoking on lung function revealed a dramatic fall in respiration symptoms in those who stopped smoking, a fair decline in those who reduced smoking by $25 \%$ and a small change in those who do not adjust their cigarette consumption habit.

Nevertheless consistency is shown by studies by [24] in some parts of Africa who found smokers having large pvalues for FVC and FEV1 in young people than non-smokers. The study demonstrated that current and previous smokers had larger p-values for FVC than those who had never smoke. "Healthy smoker effect" may be attributed to this because a smoker is likely to develop lungs resistant to effects of smoking. [25] attributed this to smokers having their lower level airways responsive enough to inhaled particles.

\section{Conclusions}

The months of December, January and February had measured $\mathrm{PM}_{10}$ concentrations exceeding both the WHO guideline limit $\left(50 \mu \mathrm{gm}^{-3}\right)$ and EPA-Ghana standard of 70 $\mu \mathrm{gm}^{-3}$. These months were the months where relative humidity was relatively lower as compared to the months of November and March.

The TSP concentrations recorded were generally below the EPA- Ghana standard of $230 \mu \mathrm{gm}^{3}$ except the months of December and January where concentrations recorded at Consar crushing site, Consar Blasting site and Poho recorded were above the EPA-Ghana standard. Also, The TSP concentrations measured generally exceeded the WHO guideline of $200 \mathrm{gm}^{-3}$ for the months of December, January and February but not November and March.

The Consar crushing and blasting sites generally recorded 
the highest TSP and $\mathrm{PM}_{10}$ concentrations because those areas are the point of generation of particulate matter. There occurred significantly higher measured lung function parameters (VC, FVC, FEV1, PEF and $\mathrm{FEF}_{25 \%-75 \%}$ ) than their respective predicted values. The study therefore revealed that the ambient air of the concessional area of the Consar Stone Quarry Limited is polluted with $\mathrm{PM}_{10}$ and TSP in the periods of low relative humidity significantly impacting negatively on the lung functions of the inhabitants.

Based on the results of the study, it is recommended that, environmental education with emphasis on the causes and effects of air pollution must be intensified in stone quarry communities by the EPA., further studies taking into consideration weekly or daily measurement of particulate matter within the month and for an extended period would ascertain the ambient air quality over such periods. This would enhance long-term decisions by management of the quarry and also law enforcement agencies. Greater attention should be paid to some air pollution mitigation measures such as frequent watering of the roads in the concessional areas of the Consar Stone Quarry Limited.

\section{References}

[1] OLUMAYEDE, E. G., SODEINDE, K. O., AKINTADE, C. O., Emmanuel, B. O., Akintoye, A., \& Peter, O. O. (2016). Different Size Aggregates of Stone Quarry Products and Airborne Particles around a Facility in Akure, Southwestern Nigeria: Radioactivity Concentrations, Radiological Hazard and Dose Assessment. Nature Environment and Pollution Technology, 15 (4), 1351.

[2] Harris, J. M., \& Roach, B. (2017). Environmental and natural resource economics: A contemporary approach. Routledge.

[3] HEI, H. E. I. 1995. Particulate Air Pollution and Daily Mortality. Replication and Validation of selected studies, 4.

[4] Olusegun, O., ADENIYI, A. \& ADEOLA, G. T. 2009. Impact of granite quarrying on the health of workers and nearby residents in Abeokuta Ogun State, Nigeria. Ethiopian Journal of Environmental Studies and Management, 2.

[5] MAHAMA, C. \& BAFFOUR, O. 2009. Management of stool land revenue in Ghana: A study of the Nkawie and Toase stools of the Atwima Nwabiagya District of the Ashanti Region. Journal of Science and Technology (Ghana), 29.

[6] MCDANIEL, C. \&GATES, R. 2001. Marketing Research. Burr Ridge, IL. Irwin/McGraw Hill.

[7] Fernandez-Bustamante, A., Sprung, J., Cartin-Ceba, R., Weingarten, T. N., \& Warner, D. O. (2018). The Aging Respiratory System: Strategies to Minimize Postoperative Pulmonary Complications. In Geriatric Anesthesiology. (pp. 179-196). Springer, Cham.

[8] Lowery, E. M., Brubaker, A. L., Kuhlmann, E., \& Kovacs, E. J. (2013). The aging lung. Clinical interventions in aging, 8, 1489.

[9] POURTAGHI, G., KAKOOEI, H., SALEM, M., POURTAGHI, F. \& LAHMI, M. 2009. Pulmonary effects of occupational exposure to welding fumes. Aust. J. Basic Appl. Sci, 3, 3291-3296.
[10] CHAN, L. \& KWOK, W. 2001. Roadside suspended particulates at heavily trafficked urban sites of Hong KongSeasonal variation and dependence on meteorological conditions. Atmospheric Environment, 35, 3177-3182.

[11] NTIM, M. 2011. Ambient Air Quality and the Health of Communities around Chirano Gold Mines Limited. Master of Science in Environmental Resource Management, Kwame Nkrumah University of Science and Technology, Kumasi.

[12] LADEN, F., NEAS, L. M., DOCKERY, D. W. \& SCHWARTZ, J. 2000. Association of fine particulate matter from different sources with daily mortality in six US cities. Environmental health perspectives, 108, 941.

[13] Thurston, G. D., Burnett, R. T., Turner, M. C., Shi, Y., Krewski, D., Lall, R.,\& Pope III, C. A. (2015). Ischemic heart disease mortality and long-term exposure to source-related components of US fine particle air pollution. Environmental health perspectives, 124 (6), 785-794.

[14] Gani, A. (2015). Air quality and under-five mortality rates in the low-income countries. The Journal of Development Studies, 51 (7), 851-864.

[15] Ostro, B., Feng, W. Y., Broadwin, R., Green, S., \& Lipsett, M. (2006). The effects of components of fine particulate air pollution on mortality in California: results from CALFINE. Environmental health perspectives, 115 (1), 13-19

[16] RICE, M. B., LJUNGMAN, P. L., WILKER, E. H., DORANS, K. S., GOLD, D. R., SCHWARTZ, J., KOUTRAKIS, P., WASHKO, G. R., O'CONNOR, G. T. \& MITTLEMAN, M. A. 2015. Long-term exposure to traffic emissions and fine particulate matter and lung function decline in the Framingham Heart Study. American journal of respiratory and critical care medicine, 191, 656-664.

[17] ALIAS, M., HAMZAH, Z. \& KENN, L. S. 2007. PM $_{10}$ and total suspended particulates (TSP) measurements in various power stations. The Malaysian Journal of Analytical Sciences, $11,255-261$.

[18] KÜNZLI, N., KAISER, R., MEDINA, S., STUDNICKA, M., CHANEL, O., FILLIGER, P., HERRY, M., HORAK, F., PUYBONNIEUX-TEXIER, V. \& QUÉNEL, P. 2000. Publichealth impact of outdoor and traffic-related air pollution: a European assessment. The Lancet, 356, 795-801.

[19] Environmental Monitoring Program, 2002.

[20] SAXENA, D. \& KUMAR, P. 2015. Prediction of peak expiratory flow rate from arm span in healthy children aged 8 to 12 years. International Journal of Biomedical Research, 6, 626-628.

[21] POURTAGHI, G., KAKOOEI, H., SALEM, M., POURTAGHI, F. \& LAHMI, M. 2009. Pulmonary effects of occupational exposure to welding fumes. Aust. J. Basic Appl. Sci, 3, 3291-3296.

[22] Héroux, M. E., Anderson, H. R., Atkinson, R., Brunekreef, B., Cohen, A., Forastiere, F., \& Künzli, N. (2015). Quantifying the health impacts of ambient air pollutants: recommendations of a WHO/Europe project. International journal of public health, 60 (5), 619-627.

[23] GOLD, D. R., WANG, X., WYPIJ, D., SPEIZER, F. E., WARE, J. H. \& DOCKERY, D. W. 1996. Effects of cigarette smoking on lung function in adolescent boys and girls. New England Journal of Medicine, 335, 931-937. 
[24] MOKOETLE, K. E., DE BEER, M. \& BECKLAKE, M. R. 1994. A respiratory survey in a black Johannesburg workforce. Thorax, 49, 340-346.

[25] BECKLAKE, M. \& LALLOO, U. 1990. The 'healthy smoker': a phenomenon of health selection? Respiration, 57, 137-144.

[26] Raju, P. S., Prasad, K. V. V., Ramana, Y. V., Ahmed, S. K., \& Murthy, K. J. R. (2003). Study on lung function tests and prediction equations in Indian male children. Indian pediatrics, 40 (8), 705-712.21.

[27] Ayaaba, E., Li, Y., Yuan, J., \& Ni, C. (2017). Occupational respiratory diseases of miners from two gold mines in Ghana. International journal of environmental research and public health, 14 (3), 337.
[28] Nartey, V. K., Nanor, J. N., \& Klake, R. K. (2012). Effects of quarry activities on some selected communities in the Lower Manya Krobo District of the Eastern Region of Ghana. Atmospheric and Climate Sciences, 2 (03), 362.

[29] Bewiadzi, S., Awubomu, R., \& Glover, N. (2018). Searching and Cracking: Stone Quarrying, Livelihood and the Environment in the Daglama Quarry Site in the Ho Municipality. West African Journal of Applied Ecology, 26, 149-166. 